\title{
Operant GSR conditioning using a within-S design'
}

JAMES R. MILSTEAD, University of Houston, Hotston, Texas 77025, PAUL E. BAER and MARCUS J. FUHRER. Baylor University College of Medicine, Houston. Tevas

Human operant GSR conditioning was attempted on a within-S basis by successively alternating periods of contingent and noncontingent reinforcement. The frequency and timing of reinforcemcnts during each noncontingent period was determined $b y$ the pattern generated during the preceding contingent period. On a group basis $(N=17)$, the frequency of nonspecific GSRs was found to be significantly greater during contingent periods of reinforcement. Evidence for a relationship between the content of postconditioning verbalizations and conditionability approached statistical reliability.

A yoked-control design has been used most frequently in studies attempting to demonstrate operant conditioning of autonomic responses in human Ss (e.g., Fowler \& Kimmel, 1962; Rice, 1966). In this design the control $S$ receives the same number and temporal pattern of reinforcements that a given experimental $S$ receives, but reinforcement is not contingent upon emission of the autonomic response being conditioned. However, according to Church (1964), results obtained by comparing the experimental and control groups may be questioned due to an artificial ceiling upon the number of responses some control Ss may emit.

The purpose of the present study was to determine if operant conditioning of the GSR could be demonstrated using an experimental design which circumvents problems raised by Church. Successive periods of contingent and noncontigent stimulation were used which permitted the $S$ to serve as his own control. A potentially reinforcing event was administered contingently upon emission of nonspecific GSRs in the presence of one discriminative stimulus $\left(S_{D}\right)$. In the presence of a discriminatively different stimulus $\left(S_{\Delta}\right)$ which followed, presentation of the reinforcing event was not contingent upon nonspecific GSR emission. Instead, the reinforcing event was administered with the same frequency and temporal pattern which occurred during the preceding $S_{D}$ period. In effect, the $S$ was yoked to himself.

There has also been a tendency in previous studies to ignore the role of cognitive variables in the operant conditioning of autonomic responses. The influence of cognitive processes is particularly important in terms of the possibility that apparent operant conditioning of autonomic responses actually depends upon mediation by voluntary behavior, e.g., respiration changes, body movements, or by mediational states of emotionality or expectancy. It was reasonable to assume that these voluntary behaviors may be monitored covertly by the $S$ during conditioning and can, therefore, be reported in a postconditioning interview. In the present study, a systematic interview was conducted so that a comparison could be made between the GSR conditioning of Ss who reported this type of behavior vs those who did not.

\section{METHOD}

Seventeen females, ages 18-35, served as paid Ss. On four channels of a Type R Offner Dynograph, the following responses were recorded: electrodermal activity from the volar aspect of a finger, heart rate, respiration frequency, and digital blood volume. The present report will be limited to electrodermal responses.

Monopolar exosomatic skin conductance changes and basal resistance were recorded by means of a constant voltage system delivering $0.4 \mathrm{~V}$. Silver-silver chloride electrodes and a neutral saline jelly were used. The active site was limited to a masked, .33 sq $\mathrm{cm}$ area which was located on the volar surface of the second phalange of the right index finger. The Ss were instructed to restrict mosement of the right hand in order to avoid movement artifacts

Visual stimuli were delivered from a panel which was located $S \mathrm{ft}$ in front of $\mathrm{S}$ at cyc level. A white light served as the reinforcing stimulus, and amber and green lights as discriminative stimuli. The signal values of the discriminative stimuli were altered for successive $S$ s.

The sequence of alternating $S_{D}$ and $S_{\mathcal{A}}$ periods began with an $S_{D}$ period which was characterized by the continuous illumination of one of the discriminative stimuli, either the green or amber light. The duration of all $\mathrm{S}_{\mathrm{D}}$ periods was $8 \mathrm{~min}$. during which the $E$ reinforced all GSR deflections exceeding $1 \mathrm{~mm}$ by flashing the white light for an automatically controlled duration of $.5 \mathrm{sec}$. Those GSRs observed to occur within $3 \mathrm{sec}$ following reinforcement were not reinforced. The $E$ recorded the timing of each reinforcement throughout each $S_{D}$ period. The $S_{\Delta}$ period onset coincided with $S_{D}$ offset, and was signaled to the $S s$ by a shift in the hue of the discriminative stimulus. The duration of the $S_{\Delta}$ period was $4 \mathrm{~min}$, with presentations of noncontingent reinforcements yoked with the administration of white lights during the last $4 \mathrm{~min}$ of the preceding $S_{D}$ period. Four complete successive alternations of $S_{D}$ and $S_{\Delta}$ were administered, followed by a standardized interview which was tape-recorded.

\section{RESULTS}

The purpose of the analyses was to compare nonspecific GSR activity during $S_{D}$ or contingent periods of stimulation with that of succeeding $S_{\Delta}$ or noncontingent periods of stimulation. The available amplification permitted nonspecific GSRs as small as $.005 \mu$ mhos to be detected and reinforced. Any GSR not occurring within $3 \mathrm{sec}$ following the onset of a discriminative stimulus or not within $3 \mathrm{sec}$ following reinforcement was considered to be a nonspecific GSR.

The summed frequencies for the $17 \mathrm{Ss}$ during the successive $S_{D}$ periods were $165,135,133$, and 140 ; and for the $S_{\Delta}$ periods, 136, 108, 107, and 122. On a group basis, the Wilcoxon test was used to compire the summed frequency (573) of nonspecifics during the last 4 min of all $S_{D}$ periods against the summed frequency (473) of nonspecifics during all $\mathrm{S}_{\Delta}$ periods. Significantly more nonspecifics were observed during $S_{D}$ periods $(T=30, N=16, p<.05)$. Two-tailed tests were used in this comparison, as well as in the ones which follow.

The possibility exists that the S's arousal levels decreased over the first part of the experiment as Ss adapted to the general experimental situation. Since the frequency of nonspecific GSRs and arousal levels tend to be positively correlated (Dykman, Reese. Galbrecht, \& Thomasson, 1959), nonspecifics would be expected to decrease in frequency. Consequently, an $\mathrm{S}_{\mathrm{D}}$ period might have a higher frequency of nonspecifics than a succeeding $S_{\Delta}$ period even if there was no differential effect of contingent vs noncontingent reinforcement. To control in part for this possibility, an attempt was made to find a point beyond which a stable level of responding was reached within each of the two types of experimental periods. This was done by direct comparison of successive $\mathrm{S}_{\mathrm{D}}$ periods and successive $S_{\Delta}$ periods. Only in the comparison of the first $S_{\Delta}$ period (summed frequency $=136$ ) with the second $\mathrm{S}_{\Delta}$ periods (summed frequency $=108$ ) was a significant difference in responding found $(\mathrm{T}=14, \mathrm{~N}=14, \mathrm{p}<.05)$. Therefore, the first pair of $S_{D}$ and $S_{\Delta}$ periods were dropped from the analysis and the data were reanalyzed using the last 
three pairs of $S_{D}$ and $S_{\Delta}$ periods. The Wilcoxon test was again used to compare the summed frequency of nonspecifics (408) during the last $4 \mathrm{~min}$ of the $S_{D}$ periods against the summed frequency (337) of nonspecifics during the $S_{\Delta}$ periods. Significantly more frequent responding was observed during $\mathrm{S}_{\mathrm{D}}$ periods $(\mathrm{T}=25, \mathrm{~N}=15, \mathrm{p}<.05)$.

As previously discussed, apparent operant conditioning of autonomic responses may be mediated by voluntary behaviors. It was posited that these behaviors may be monitored covertly by the $S$ during conditioning and could be reported in the postconditioning interview. To investigate this possibility, three raters, working separately, analyzed the content of the interviews. The content-analysis focused upon the Ss' conceptualizations of a possible contingency between their own behavior and occurrence of the reinforcing light. On the basis of the content analysis, eight Ss were placed in a "Relevantly Verbalizing" group and seven Ss were placed in an "Irrelevantly Verbalizing" group. The Relevantly Verbalizing group consisted of Ss who were independently judged by at least two of the three raters to have hypothesized some relation between the reinforcing event and their own behavior. Adequate tape-recordings were unavailable for two interviews.

The GSR data for the Relevantly Verbalizing and Irrelevantly Verbalizing groups then were separately analyzed within each group. The summed frequency of nonspecifics during the last $4 \mathrm{~min}$ of the last three $S_{D}$ periods was compared to the summed frequency of nonspecifics during the last three $S_{\Delta}$ periods. The summed frequencies for $S_{D}$ and $S_{\Delta}$ periods for the Relevantly Verbalizing group were 257 and 194, respectively, and for the Irrelevantly Verbalizing group, 131 and 127, respectively. The differences approached significance for the Relevantly Verbalizing group $(T=3$, $\mathrm{N}=7, \mathrm{p}<.10$ ). For the Irrelevantly Verbalizing group, the difference was not statistically significant $(T=11, N=6$, $\mathrm{p}>.10$ ).

\section{DISCUSSION}

The primary goal of the study appears to have been fulfilled since evidence was obtained that may be interpreted as a successful demonstration of operant GSR conditioning on a within-S basis. That is, the frequency of nonspecific GSRs was significantly greater when presentation of a visual stimulus was contingent upon GSR emission than during noncontingent periods when presentation of the stimulus was independent of GSR emission. As mentioned, an alternate interpretation is possible, however, due to the possibility that Ss' arousal levels may have been changing during the session. This possibility is attenuated by the observation that significant differences between contingent and noncontingent periods were still obtained after stable levels of responding were reached within the two types of periods.

\section{REFERFNCES}

CHURCH, R. M. Systematic effect of random error in the yoked control design. Psychological Bulletin, 1964, 63, 122-131.

DYKMAN, R. A., REESE, W. G., GALBRECHT, C. T., \& THOMASSON P. S. Psychophysiological reactions to novel stimuli: Measurement, adaptation, and relationships of psychological and physiological variables in the normal human. Annals of the New York Academy of Sciences, 1959, 79, 43-107.

FOWLER, R. L., \& KIMMEL, H. D. Operant conditioning of the GSR. Journal of Experimental Psychology, 1962, 63, 563-567.

RICE, D. G. Operant conditioning of the GSR and associated electromyogram responses. Journal of Experimental Psychology, $1966,71,908-918$.

\section{NOTE}

1. Supported in part by Public Health Service Grants MH 11939-01 and MH 12908-01; the Social and Rehabilitation Service, Department of Health, Education and Welfare, Research and Training Center RT-4; and the Texas Research Institute of Mental Sciences. Based on a M.A. thesis by the first author under the direction of the latter authors. 